\title{
Experimental Observations of Natural Circulation Flow in the NSTF
}

\author{
Darius D. Lisowski, Adam R. Kraus, Matthew D. Bucknor, Rui Hu, Mitch T. Farmer
}

Argonne National Laboratory

9700 S. Cass Avenue, Lemont IL 60439. USA

Phone: +1 630-252-1128, dlisowski@anl.gov

\begin{abstract}
A $1 / 2$ scale test facility has been constructed at Argonne National Laboratory (ANL) to study the heat removal performance and natural circulation flow patterns in a Reactor Cavity Cooling System (RCCS). Our test facility, the Natural convection Shutdown heat removal Test Facility (NSTF), supports the broader goal of developing an inherently safe and fully passive ex-vessel decay heat removal for advanced reactor designs. The project, initiated in 2010 to support the Advanced Reactor Technologies (ART), Small Modular Reactor (SMR), and Next Generation Nuclear Plant (NGNP) programs, has been conducting experimental operations since early 2014. The following paper provides a summary of some primary design features of the 26-m tall test facility along with a description of the data acquisition suite that guides our experimental practices. Specifics of the distributed fiber optic temperature measurements will be discussed, which introduces an unparalleled level of data density that has never before been implemented in a large scale natural circulation test facility. Results from our test series will then be presented, which provide insight into the thermal hydraulic behavior at steady-state and transient conditions for varying heat flux levels and exhaust chimney configuration states.
\end{abstract}

(C) 2016. This manuscript version is made available under the Elsevier user license 


\section{INTRODUCTION}

There is a recognized need to address the safety requirements of advanced future nuclear reactors. Recent events have focused part of this effort on developing fully passive and inherently safe decay heat removal systems. One concept under consideration, the Reactor Cavity Cooling System (RCCS), is geared towards the latest generation of high temperature gas cooled reactors (HTGR) and provides an entirely ex-vessel means to reject decay heat to the environment without the need for pumps, diesel generators, or human intervention.

Relying primarily on radiative heat transfer from the walls of the reactor pressure vessel (RPV), the design philosophy for the RCCS is centered on natural circulation driven flow to successfully remove decay heat. The inherent sensitivity of these buoyancy driven systems, augmented by multiple parallel flow paths, introduces certain complexities that are often difficult to predict with computational models alone. The onset of flow instabilities may be triggered by minor perturbations and result in undesirable behavior or reduced performance. Thus, there is value in experimental validation, which the Natural convection Shutdown heat removal Test Facility (NSTF) at Argonne National Laboratory ("Argonne") aims to address.

\section{FULL SCALE DESIGN CONCEPT}

The focus of this paper will be a scaled experimental investigation of one specific design concept by General Atomics (GA) for their Modular High Temperature Gas cooled Reactor (MHTGR). To support the experimental investigation, the computational analyses $[1,2]$ of the NSTF are being performed concurrently. Developed in the United States, the MHTGR design uses prismatic fuel elements within a hexagonal core, helium as the primary coolant, and is proposed via four unit plants and two steam turbines for a total power output of approximately $350 \mathrm{MW}_{\mathrm{e}}[3]$.

For each reactor within the four-unit plant, the design by GA proposes separate air-cooled RCCS networks that are integrated into each containment building. These systems will operate continuously and not require operator invention in an accident scenario. The specific design under consideration is estimated to remove $700 \mathrm{~kW}_{\mathrm{t}}$ under normal operation (parasitic losses), and sized to remove up to $2.2 \mathrm{MW}_{\mathrm{t}}$ (decay heat) under accident conditions when loss of cooling occurs in the primary system.
Serving as the primary means of decay heat removal, the RCCS comprises a series of ductwork (risers, plenums) and chimneys. The risers line the reactor containment and surround the RPV circumferentially and are joined via plenums to intake and exhaust chimney circuits, Fig. 1. The rectangular riser ducts, 227 in total number and each $5-\mathrm{cm}$ by $25-\mathrm{cm}$ in cross sectional area [4] span the full height of the concrete containment and serve also to protect the concrete from heat induced degradation.

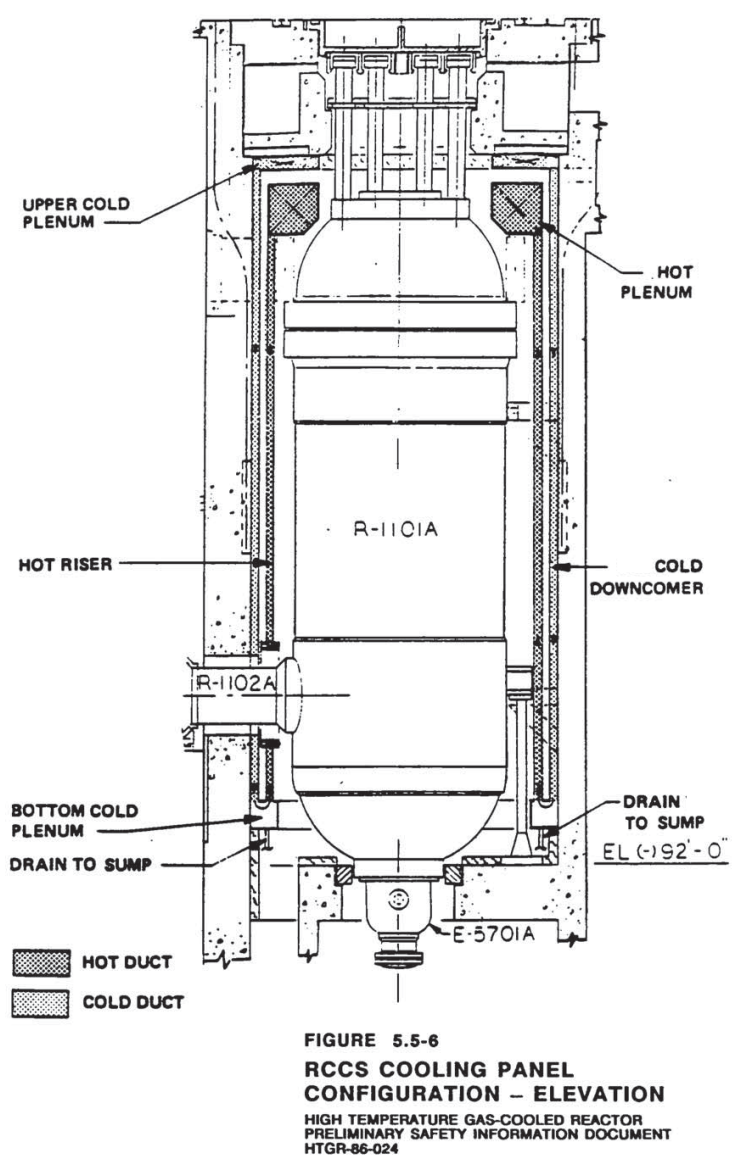

Fig. 1: GA-MHTGR RCCS concept [4]

\section{EXPERIMENT DESCRIPTION}

An air-based test facility has been constructed at Argonne to investigate this design concept for passive decay heat removal. Modeled after the full scale RCCS design by GA described above, the NSTF contains 12 riser ducts $\left(19.03^{\circ}\right.$ sector slice $)$ at a reduced $1 / 2$ scale, and stands $26-\mathrm{m}$ in overall height. Previous works at Argonne have outlined the scaling studies that were performed to ensure the preservation of key thermal hydraulic phenomena, 
similarity among scales, and validity among the generated data sets [5].

The test facility features a single inlet downcomer, an inlet plenum, twelve riser ducts within a heated cavity that serve as the test section, an outlet plenum, and dual symmetric exhaust ducts, Fig. 2. The low elevation inlet, dissimilar to the full scale concept, was chosen to facilitate test operations and reduce construction complexity. This influence however will be studied at a future date with a subset of tests where the inlet will be rerouted to an elevation equal to the outlet.

Operator driven flexibility has been integrated into the test facility and includes controls for zoning of the heated test section, variations on heated surface - riser duct spacing, inlet and outlet ductwork configurations, and varying chimney roles. The planned test series spanned an exhaustive parameter set that included investigations onto these variables.

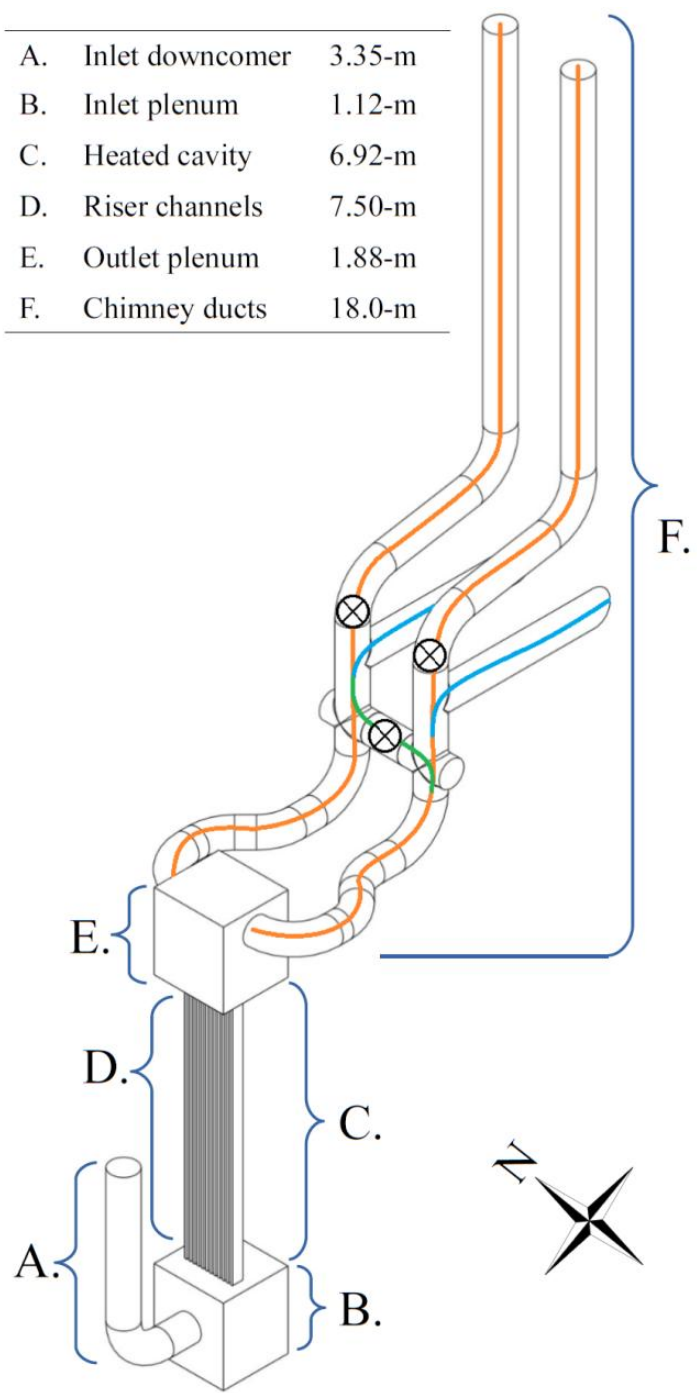

Fig. 2: Simplified line model of the NSTF. Flow paths shown for varying chimney roles: baseline (orange), reduced discharge (blue), single chimney (green). Crossed circles represent valves. Vertical elevations of components provide by inset table.
A suite of more than 400 data acquisition channels guides test operations and serves to monitor key thermal hydraulic phenomena. Measurements of system mass flow rates, differential pressure drop, surface and gas temperatures, among others, are included in this suite. A summary is provided in Table 1, with additional details such as the heater configuration and insulation properties provided in earlier works by the authors $[6,7]$.

Table 1: NSTF instrumentation summary

\begin{tabular}{|l|c|c|c|}
\hline Instrument & Location & $\#$ & Range \\
\hline Flow rate $^{1}$ & Inlet & $\mathrm{x} 1$ & $0-1 \mathrm{~kg} / \mathrm{s}$ \\
\hline$\Delta \mathrm{P}_{\text {heated }}{ }^{1}$ & Risers & $\mathrm{x} 8$ & $\pm 62.2 \mathrm{~Pa}$ \\
\hline$\Delta \mathrm{P}_{\text {adiabatic }}{ }^{3}$ & Chimney & $\mathrm{x} 2$ & $\pm 24.8 \mathrm{~Pa}$ \\
\hline Humidity $^{4}$ & Inlet & $\mathrm{x} 1$ & $3-95 \% \mathrm{RH}$ \\
\hline Heat flux $^{5}$ & Risers & $\mathrm{x} 16$ & $0-300 \mathrm{~kW} / \mathrm{m}^{2}$ \\
\hline Temperature $^{6}$ & various & $\mathrm{x} 368$ & Type-K \\
\hline Wind speed & Roof & $\mathrm{x} 1$ & $1-80 \mathrm{~m} / \mathrm{s}$ \\
\hline Wind direction & Roof & $\mathrm{x} 1$ & $0-360^{\circ}$ \\
\hline Humidity & Roof & $\mathrm{x} 1$ & $1-100 \% \mathrm{RH}$ \\
\hline Ambient temp. & Roof & $\mathrm{x} 1$ & $-40-60^{\circ} \mathrm{C}$ \\
\hline \multicolumn{4}{|c|}{$[1]: \pm 1 \%+0.3 \mathrm{~kg} / \mathrm{min},[2] \pm 1 \%,[3] \pm 0.5 \%$} \\
& {$[4]: \pm 2 \%,[5]: \pm 5 \%,[6]: \mathrm{SLE} \pm 1.1{ }^{\circ} \mathrm{C}$ or $0.4 \%$} \\
\hline
\end{tabular}

While it is expected that thermal radiation will be the primary mode of heat transfer, the heated cavity (essentially an internal enclosed environment) allows natural circulation cells to develop and grow. Similar to the enclosed containment in a full scale design, contributions from convection aid in the overall heat transfer from the RPV to the riser ducts.

To quantify the split between convective and radiative heat transfer, specialty heat flux sensors have been installed in pairs along the duct walls in the NSTF. Each pair consists of one sensor that has a black, matte surface $(\varepsilon \approx 1)$, while the other sensor has a shiny, reflective surface $(\varepsilon<<1)$, Fig. 3 . The black surface will absorb both radiation and convection portions of heat transfer, while the shiny will reflect the majority of radiation and instead measure those contributions solely from convection.

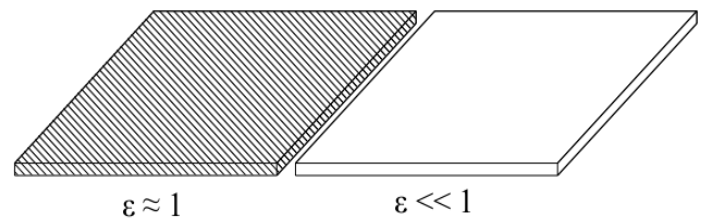

Fig. 3: Heat flux sensor pairs. Black matte (left), shiny reflective (right)

\section{EXPERIMENTAL PROCEDURE}

Testing operations began by verifying cold-start, zero-flow conditions. A period of no less than 5 days was allowed to ensure that any residual heat was naturally dissipated from the massive steel structures 
and that the facility and laboratory space were allowed to reach ambient temperatures. Inlet and outlet ductwork were closed and zero-flow values were confirmed for the hydraulic instrumentation, and thermocouples were compared to ensure nominal values (natural gradients existed due to the 26-m height of the facility).

Test operations and active heating then began by supplying a 3-hour power ramp to $56 \mathrm{~kW}_{\mathrm{e}}$, allowing the facility to stabilize for 24 hours, and then initiating a $2^{\text {nd }}$ power ramp to $78 \mathrm{~kW}_{\mathrm{e}}$, Fig. 4. The $2^{\text {nd }}$ and final power ramp allowed the test to approach the desired $56 \mathrm{~kW}_{\mathrm{t}}$ test section power, and was held for a minimum duration of 12 hours to allow averaged steady-state values to be measured. The test was concluded by a 4 hour power ramp to 0 $\mathrm{kW}_{\mathrm{e}}$ and dampening of the outlet valves to allow for a gradual cool down and ensure no thermal shock was experienced by the ceramic heaters or heated plate.

The power ramps were employed to prevent thermal shock to the steel structure, minimize thermal gradient along the massive $2,000 \mathrm{~kg}$ heated steel plate, and ensure that the delicate ceramic heaters were not damaged by a sharp temperature excursion. The two power levels were selected first based on an electric equivalent of the desired thermal power, allowing the operator to determine the nominal heat losses. The second power level was determined by an estimated electric power that would provide the desired thermal power.

In this context, electric power, $\mathrm{kW}_{\mathrm{e}}$, is defined by the electric energy supplied to the heaters, while thermal power, $\mathrm{kW}_{\mathrm{t}}$, is calculated and based on the power removed by the gas within the test section.

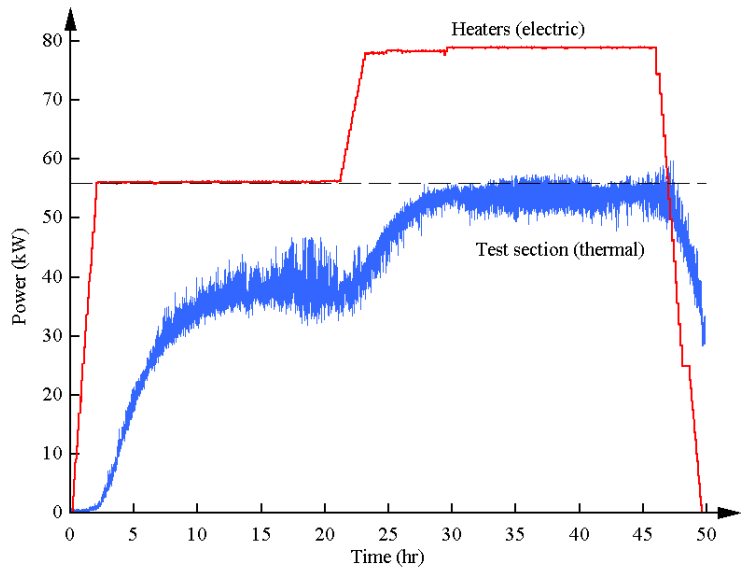

Fig. 4: Electric and thermal powers for baseline test case, dual vertical chimney exhaust. Scatter in thermal power is the result of natural fluctuations in the system flow rate from wind effects.

\section{BASELINE TEST RESULTS}

The baseline test case for experimental operations in the NSTF defined $56 \mathrm{~kW}_{\mathrm{t}}$ within the test section, which was achieved by supplying a nominal $78 \mathrm{~kW}_{\mathrm{e}}$ in a uniform profile to the zoned electric heater banks. The outlet gases were vented through the vertical chimney stacks and the riser tube - heated plate spacing was kept constant at 71$\mathrm{cm}$.

\section{V.A. Heat flux distribution}

The split in heat flux distribution for the baseline test case is shown as a function of axial position in Fig. 5. The power transferred from the heated plate to the riser ducts is dominated by radiation, averaging $70 \%$ with the remaining $30 \%$ contribution from convection.

The downward trends of the convective portion near the lower and upper cavity extents can be attributed to the natural circulation patterns near the corners of the heated enclosure. Along the bulk length the hot air is able to build momentum and increase its effectiveness, whereas nearest the corners it experiences a reduction in velocity and thus a reduced convection heat transfer coefficient.

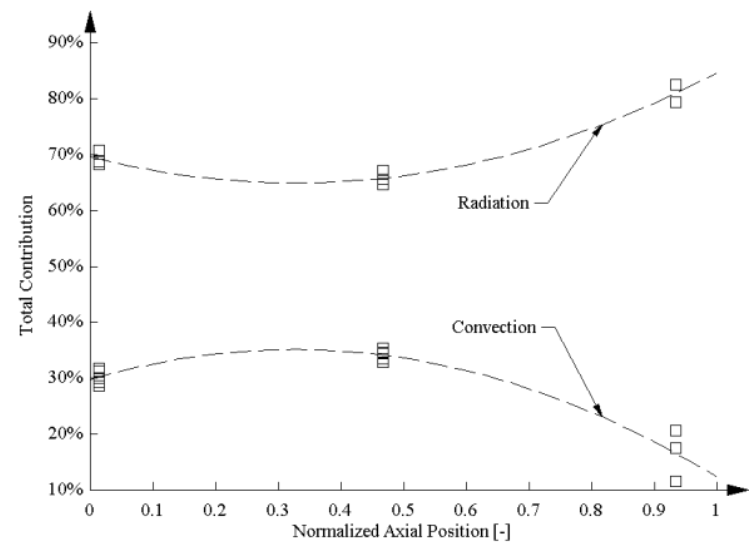

Fig. 5: Heat flux distribution from heated plate to front surface of riser ducts, baseline case

For the tested power levels, measured values of the heat flux varied widely along the length of the hot faces of the riser ducts, Fig. 6. The highest values during baseline conditions measured 4.4 $\mathrm{kW} / \mathrm{m}^{2}$ along the heated side nearest the mid-plane of the ducts. Lowest values were recorded near 1.5 $\mathrm{kW} / \mathrm{m}^{2}$, which occurred at lower elevations of the duct walls.

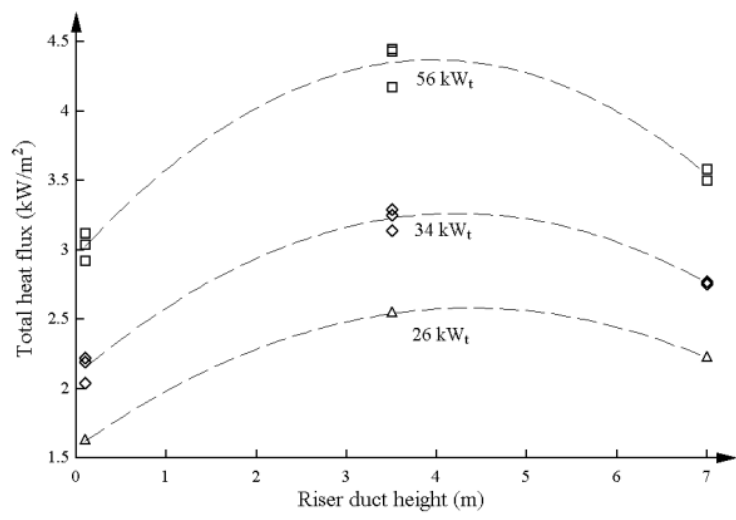

Fig. 6: Axial distribution of total heat flux on hot riser face for varying thermal powers 
Finally, the convection portion of the total heat flux was isolated and examined as a function of varying thermal powers, Fig. 7. Readily apparent is the reduction in convection and favoring towards radiation heat transfer with increasing thermal powers. This shift is explained by the $\mathrm{T}^{4}$ dependence on radiative heat transfer: with increasing thermal power the surface temperature rises, which augments the surface to surface temperature difference.

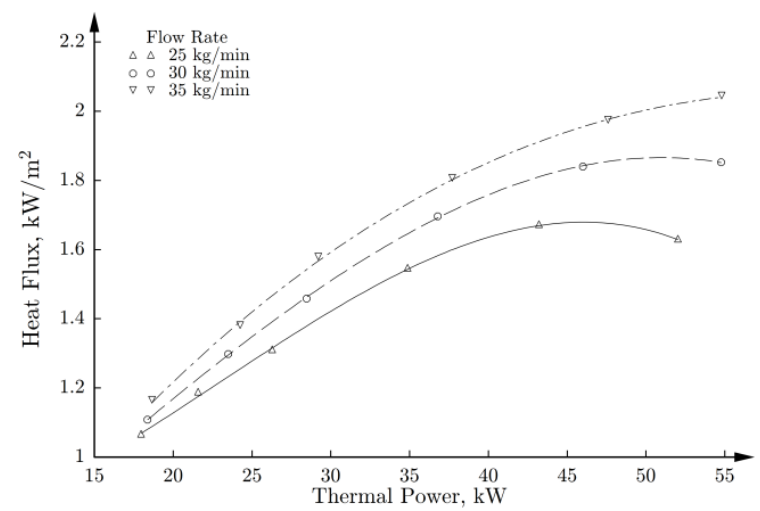

Fig. 7: Convective portion of heat flux, averaged across risers at varying flow rates vs thermal power

\section{V.B. Heated plate profile}

The heated plate within the NSTF, mimicking the walls of a RPV, was supplied with a uniform heat flux for all the test cases presented. However, due to natural circulation convection cells both within the heated cavity and convection within the riser ducts themselves, a natural temperature gradient exists along the length of the plate. Fig. 8 shows the temperature distribution of the front surface of the heater plate with $78 \mathrm{~kW}_{\mathrm{e}}$ of supplied power from the back surface, and is representative of the remaining test cases presented.

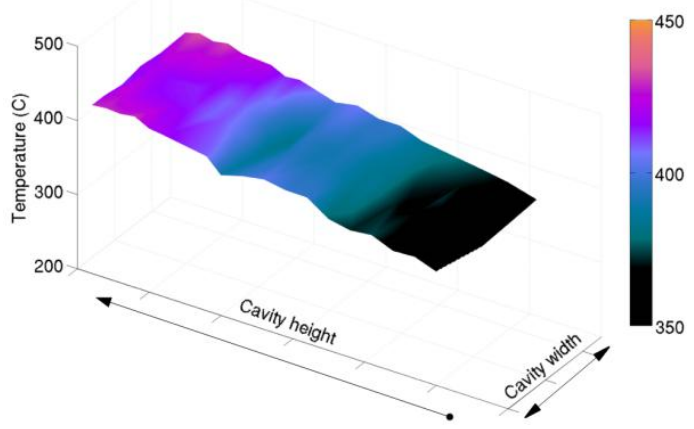

Fig. 8: Heated plate temperature profile, baseline. $10.2 \mathrm{~m}^{2}$ contour interpolated across 108 points

\section{V.C. Differential pressure drop}

The total differential pressure drop over the heated test section is a combined effect mainly from gravitational forces and frictional losses. Since the physical measurement consists of impulse tubing that connects 'low' and 'high' pressure taps to a single point, a correction has been added to create a measurement of physical meaning, Eqn. 1.

$$
\Delta \mathrm{P}_{\text {total }}=\Delta \mathrm{P}_{\text {device point }}+\Delta \mathrm{P}_{\text {grav. impulse }}
$$

Fig. 9 shows the relation between measured pressure drops as a function of system mass flow rate.

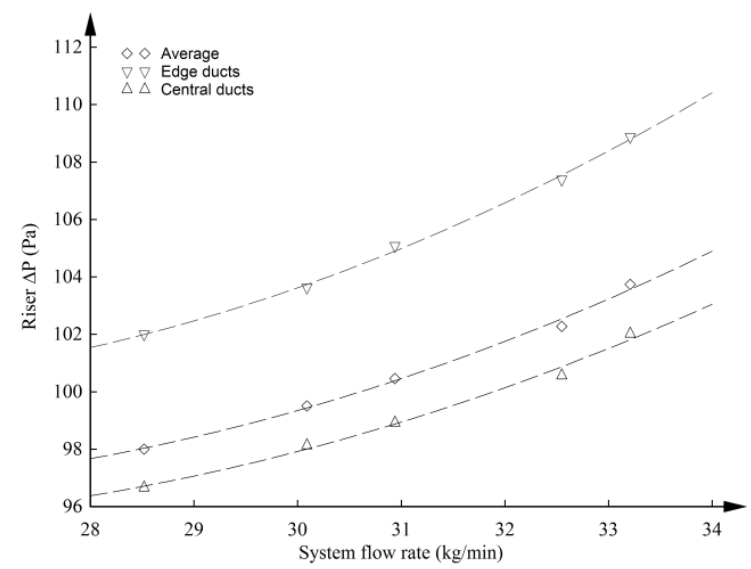

Fig. 9: Riser $\Delta \mathrm{P}_{\text {total }}$ vs. system mass flow, baseline configuration at varying integral powers

Readily apparent is a difference among the edge and central riser ducts. However, thermocouple measurements of the inlet and outlet air flow show that the temperatures across all twelve ducts are similar within the bounds of experimental error. This suggests that the influences from gravitational effects may be considered uniform across the row of risers and that the variation can be attributed to differences in frictional losses or flow velocities. Considering that a uniform heat flux has been imposed, this finding is of great interest and is currently being examined with detailed 3D analysis of the flow field.

\section{STARTUP AND METEOROLOGICAL SENSITIVITY}

Characteristic to natural circulation loops, the NSTF exhibits certain sensitivities to ambient meteorological conditions. These influences manifest themselves throughout the full duration of test operations, and are especially prevalent during start-up transients. A weather station, model Davis VantageVue, mounted on the roof of the building nearest the exhaust stacks, provides this critical time-synced weather data.

\section{VI.A. Off-normal chimney roles}

When exhausting through both vertical chimney stacks (orange flow paths in Fig. 2), a common occurrence is that an abrupt and prolonged shift in wind patterns will perturb the chimney roles and flow directions. 
Fig. 10 shows a scenario during start-up of the NSTF where a shift in wind direction and speed created a disturbance in the pressure at the outlet of the chimneys. Given the low total pressure differential across both chimney ducts (nominally 5 - $9 \mathrm{~Pa}$ for frictional losses) this disturbance can create an unequal split in flow distribution. Originating as an oscillating pattern, if left unmitigated the result is one chimney becoming a fresh air inlet and the other an outlet for both the newly formed inlet and heated exhaust gases from the riser ducts.

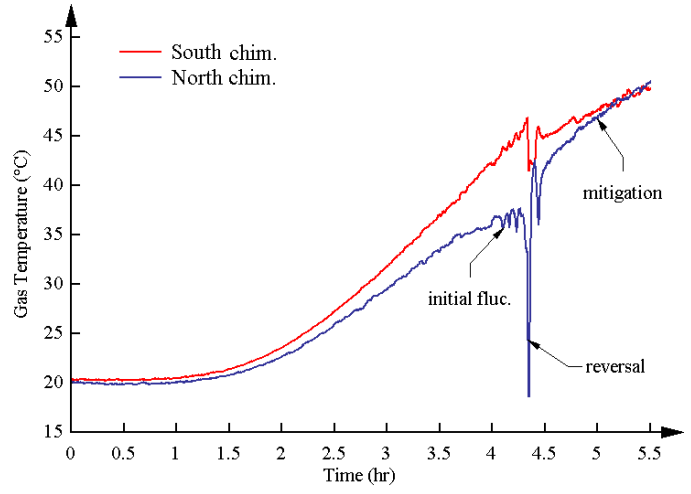

Fig. 10: Start-up instability, baseline case

This scenario was mitigated by dampening the south chimney valve, which created constriction on the flow in the south chimney. This flow reduction allowed a buildup in the heated gravitational head that then began to travel out of the lower resistance north chimney network. Once this heated air succeeded in traveling the full length of the north network it began to heat up the metal ducts and revitalized the self-sustaining natural circulation flow path.

\section{VI.B. Full system flow reversals}

Another behavior that has been observed during testing is a full system reversal during the start-up transient in a reduced chimney discharge height (blue flow path in Fig. 2). Fig. 11 shows the startup behavior where such a condition was observed.

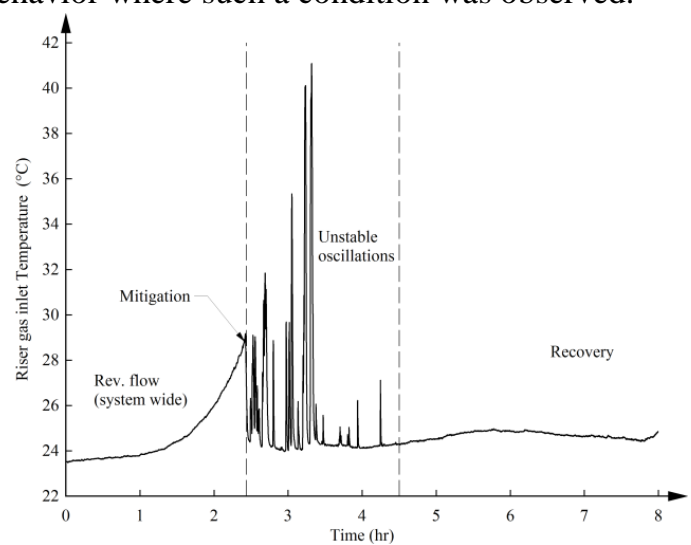

Fig. 10: Starting instability, reduced height
The reduction in exit elevation tends towards a U-loop versus a chimney column. It significantly reduces the driving head of the natural circulation flow, and thus is more sensitive to flow reversals.

Between hours 1 and 2.5 the riser inlet gas temperature exhibited a temperature rise while the riser outlet gas temperatures (not shown) remain constant and equal to the outside ambient temperature. This scenario was also mitigated by artificially dampening the valves near the chimney exhausts, allowing the system to build up positive pressure and prime the metal ductwork, and reopening the valves once the gravitational driving force was sufficiently developed to resume the asintended flow direction.

These valves, or dampers, installed in the NSTF are placed to facilitate experimental operations and guide test practices. Their use is instrumental in establishing zero-flow conditions, creating single or dual chimney configurations, and playing an active role in mitigating weather-induced flow reversals. However, they do not represent the inherently safe and fully passive philosophy of the full scale RCCS design. The instabilities observed in the experimental test facility raise important questions on the engineering controls and real world implementation of such a safety system, and are an area that has received additional considerations. However, this concern is largely limited to start-up transients since a full scale RCCS is assumed to be always in-operation.

Recent developments have seen the study and design of an optimized anti-downdraft weather cap. Testing with these new weather caps, which are fully passive and are aimed to omit the need for operator intervention, is currently underway and will be presented in future works by the authors.

\section{VI.C. Building Temperature and Pressure Effects}

The majority of the NSTF is housed inside a building at Argonne, with only a portion of the exhausting chimney ducts directly exposed to the outside environment. The presence of the building influences the performance of the facility, which can be observed in the experimental data. An example of these effects can be observed when comparing the mass flow rates of baseline tests, which are shown in Fig. 11. The active heating power profile (shown earlier in Fig. 4) for all four tests was identical, yet the response of the system varied between the tests. While the differences are due to multiple factors, the building interior temperature and building pressure effects are likely two of the more dominant factors.

In the steady-state periods of the tests (from approximately 30 hours to 45 hours), the mass flow rate of Run011 is the highest (on average) of the four tests, while the mass flow rate of Run020 is the lowest. A major difference between the conditions during which these tests were conducted is the riser 
inlet air temperature (interior air temperature of the building in which the NSTF is located) of Run020 was significantly higher than that of Run011.

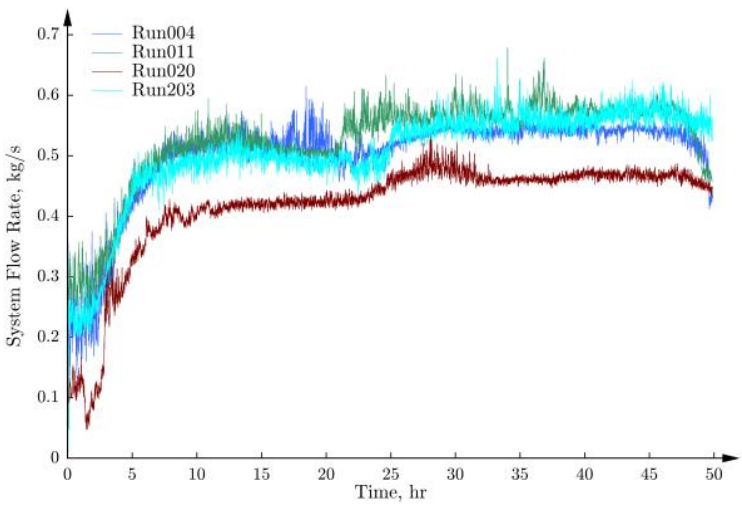

Fig. 11: Mass flow rates of various baseline tests

The approximate average riser inlet temperatures during these steady-state periods are provided in Table 2. The riser inlet air temperature of Run020 was approximately $11^{\circ} \mathrm{C}$ higher than that of Run011 because Run020 was conducted during the summer while Run011 was conducted during the winter months (the interior building temperature was maintained at approximately $20^{\circ} \mathrm{C}$ by the HVAC system of the building during Run011).

Table 2: Steady-state averags, four baseline tests

\begin{tabular}{|c|c|c|}
\hline Run No. & Air Inlet, $^{\circ}$ C & System Flow, kg/s \\
\hline Run004 & 23.55 & 0.543 \\
\hline Run011 & 19.74 & 0.574 \\
\hline Run020 & 30.66 & 0.465 \\
\hline Run203 & 23.86 & 0.561 \\
\hline
\end{tabular}

One can observe that standard air density does not decrease linearly with increasing temperature, Fig. 12. As the air temperature increases, the rate of change of air density with respect to temperature subsequently decreases.

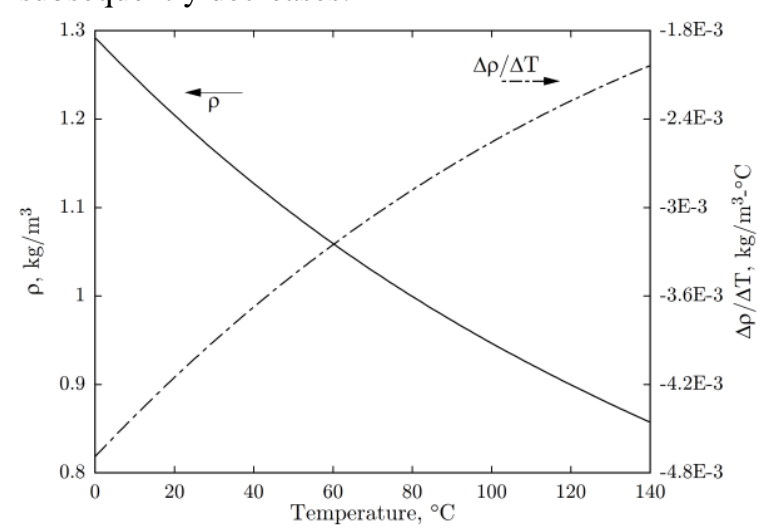

Fig. 12: Air density and temperature relationship (secondary y-axis shows negative values)

Therefore, at steady-state flow conditions, higher inlet temperatures will lead to lower density differences between the air in the inlet downcomer and the air in the riser ducts and chimney ducts. This lower density difference in Run020 results in a lower driving head, thus lower mass flow rate through the system even though the input power of the test was identical to the other baseline tests.

It should also be noted that the differences between the mass flow rates for the various baseline tests cannot be fully attributed to inlet air temperature effects. Building pressure effects certainly play a role as well, including the presence of the building, wind effects, and the air temperature differences between inside and outside of the building. These all can create pressure differences between the interior and exterior of the building that influence the system mass flow rate during testing. While efforts are currently being conducted to better understand and quantify these effects, it is possible to make qualitative remarks of the role these factors have on the experimental data.

During winter months, building interior air temperatures are typically higher than that of the exterior. This results in a net negative pressure at lower elevations of the building and a net positive pressure at higher elevations in the building [8]. The pressure differences cause building exterior air to leak into the building at the lower elevations and increase the stack effect within the NSTF. During summer months, building interior air temperatures are typically lower than that of the exterior. This results in a net positive pressure at lower elevations of the building and a net negative pressure at higher elevations of the building [8]. The pressure differences cause building interior air to leak out of the building at lower elevations, which can reduce the stack effect within the NSTF.

\section{GENERAL SYSTEM TRENDS}

The test series thus far have examined a range of supplied integral heater power for both single and dual chimney configurations. Each of these tests followed a similar procedure to the baseline test case, and was allowed to reach steady-state conditions across the range of thermal powers. Time-averaged thermal hydraulic parameters of interest are provided in tabulated form in Table 3, which were measured during a 12 hour period.

Table 3: Steady-state averages for baseline test

\begin{tabular}{|c|c|}
\hline System Parameter & Steady-state Value \\
\hline Heater power $^{1}$ & $78.67 \mathrm{~kW}_{\mathrm{e}}$ \\
\hline Thermal power ${ }^{2}$ & $53.81 \mathrm{~kW}_{\mathrm{t}}$ \\
\hline Front plate $^{3}$ & $393.9^{\circ} \mathrm{C}$ \\
\hline Ceramic heaters & $577.7^{\circ} \mathrm{C}$ \\
\hline Riser duct wall & $172.2^{\circ} \mathrm{C}$ \\
\hline Cold (unheated) wall & $148.3^{\circ} \mathrm{C}$ \\
\hline Riser gas outlet $^{4}$ & $119.9^{\circ} \mathrm{C}$ \\
\hline System flow rate & $0.548 \mathrm{~kg} / \mathrm{s}$ \\
\hline$\Delta \mathrm{P}_{\text {heated }}$ & $103.01 \mathrm{~Pa}$ \\
\hline
\end{tabular}


The responses of the heated plate surface, riser wall temperature, and riser gas temperature rise are shown for varying heater powers in Fig. 13, 14, and 15 , respectively. Additionally, the effect on system mass flow rate with single vs. dual chimney configurations is shown in Fig. 16.

A linear relation can be observed for the riser outlet gas temperatures with increasing thermal power, however those specific to the heated surface temperatures exhibit a non-linear trend by a reduced slope with increasing power. As the power increases, the surface temperatures of the riser ducts, un-heated back cavity, and heated surfaces taper off which can be expected for the $\mathrm{T}^{4}$ relation of radiative heat transfer.

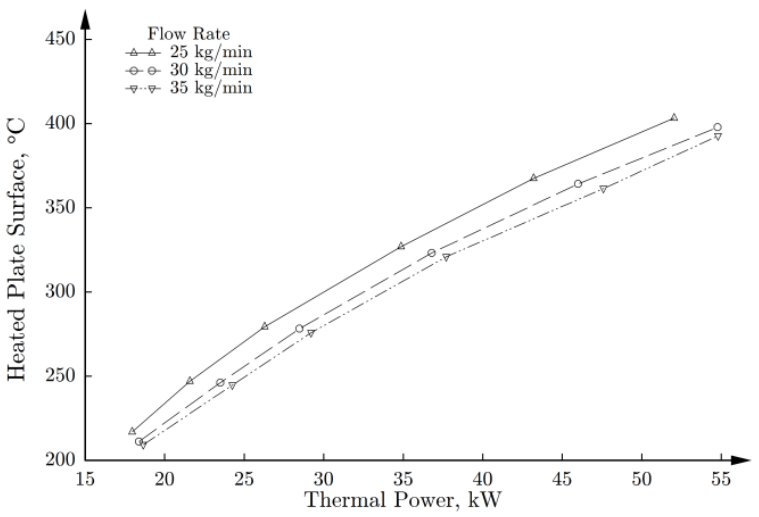

Fig. 13: Heated plate surface temperature, average across full $10.2 \mathrm{~m}^{2}$ area, vs thermal power

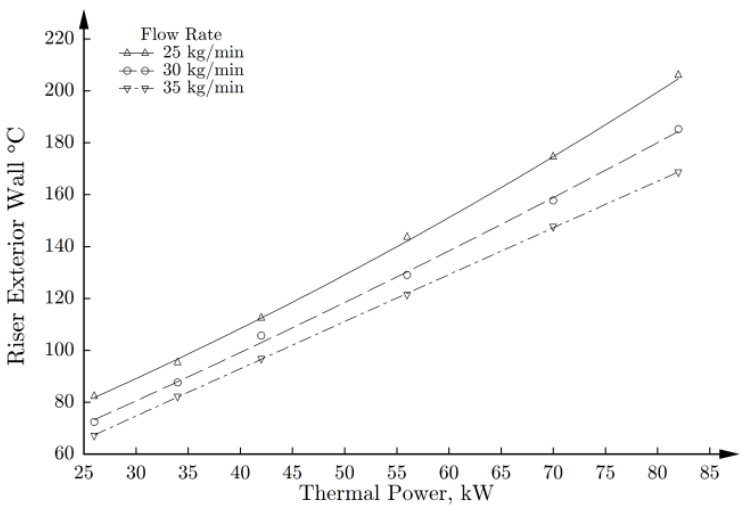

Fig. 14: Riser duct wall, average across both hot and cold faces, vs thermal power

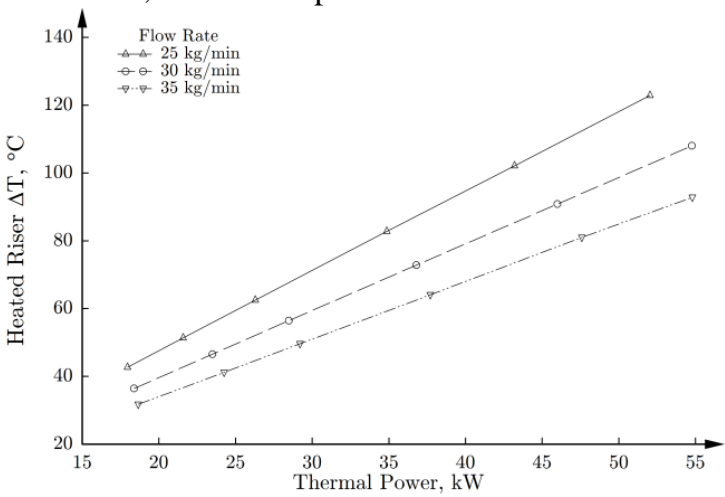

Fig. 15: Riser temperature rise, $\Delta \mathrm{T}$ inlet to outlet, vs thermal power

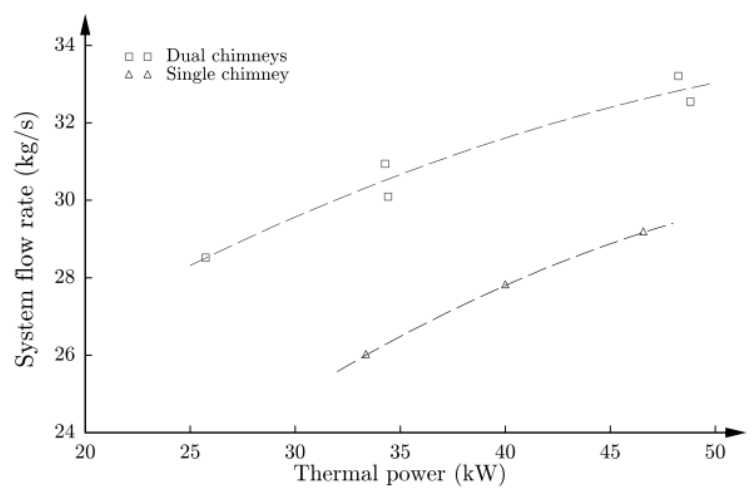

Fig. 16: System mass flow rate vs thermal power with single and dual chimney configurations

\section{INSTRUMENTATION AND SEPARATE EFFECTS TESTING TO AID COMPUTATIONAL MODELING}

Several of the most recent additions to the instrumentation suite within the experimental test facility have been solely for the purposes of supporting computational modeling. Some of the additions aim to provide specific data points for comparison with computational results. Other additions help to provide more detailed boundary conditions for the simulations.

\section{VIII.A. Hot-Wire Probes}

A fleet of hot-wire probes was installed to obtain high-resolution velocity measurements, including mean and RMS values. The probes are miniature straight-wires with a 3-mm OD body and $10 \mu \mathrm{m}$ tungsten wire capable of measuring velocities between 0.2 and $500 \mathrm{~m} / \mathrm{s}$ at a maximum process temperature of $300{ }^{\circ} \mathrm{C}$. They are simultaneously sampled at $50 \mathrm{kHz}$, which allows for calculation of high-order flow statistics, notably turbulence intensity [9]. Inclusion of the hot-wire data is important because the bulk of the other measurements in the NSTF are solely temperaturebased. The high-order statistics are also useful for more rigorous comparisons of turbulence models in computational fluid dynamics (CFD) codes.

Fig. 17 provides an example of an isothermal benchmark test in a region immediately downstream of the flow conditioner, where the turbulence intensity is significantly higher than would be seen in fully developed and bare pipe flow. Combined with results from pressure taps across this region, polynomial fits to these results can be applied as outlet conditions for the flow conditioner region, precluding the need to computationally model the conditioner in detail. Fig. 18 provides similar results for average intensity at the riser duct exits. 


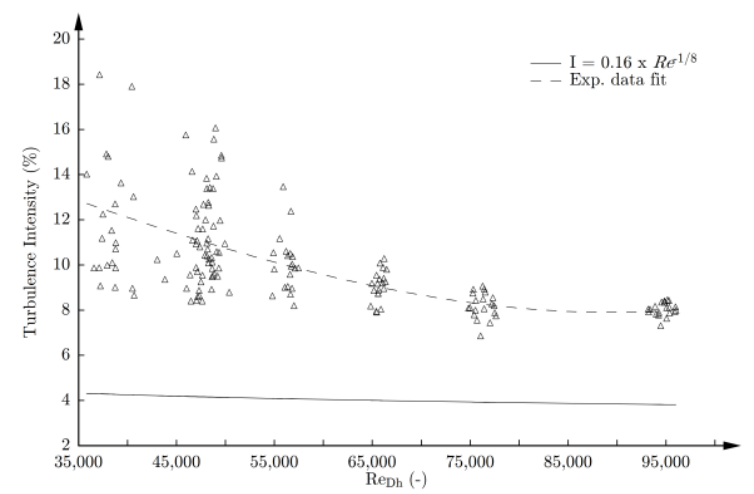

Fig. 17: Turbulence intensity measurements downstream of the flow conditioner via hot-wire

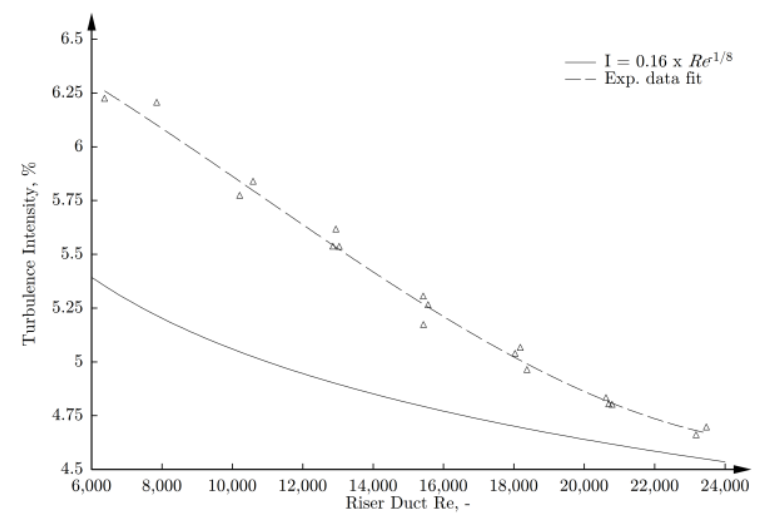

Fig. 18: Turbulence intensity measurements averaged across the riser duct outlets.

\section{VIII.B. Distributed Temperature Sensing}

Unique to the NSTF is the installation of fiber optics for high density temperature measurements. This distributed temperature sensing (DTS) system, developed by Luna Technologies, has the potential to provide the necessary data density for validation of CFD tools. This technology is relatively novel and has not been utilized in a large scale thermal hydraulic test facility.

Based upon distributed strain sensing, the system leverages Rayleigh scattering losses from structural inhomogeneities in conventional (off the shelf) fiber cables [10]. The fibers, made from $155-\mu \mathrm{m}$ polyimide-coated single mode commercial telecom fibers, are able to generate temperature measurements every $10 \mathrm{~mm}$ at $1 \mathrm{~Hz}$ for a total of 9,750 data point/s along each of the $7.5-\mathrm{m}$ fibers installed in the NSTF.

It was suggested in part through CFD analyses that the temperature distribution within the riser ducts is highly non-uniform, with strong temperature gradients found near the duct walls [11]. This is an indication that single-point thermocouple measurements may not provide a good representation of the average gas temperature at the duct exit. To improve this, as well as provide further high-resolution data for code validation, an additional DTS fiber was installed lengthwise across the outlet of each riser. An example of the data from these fibers over time is provided in Fig. 19. Data from the fiber, averaged over a duct length, shows that there is on the order of $10 \%$ more heat being removed directly by the main NSTF flow than would be suggested by a single centerline thermocouple alone. This is an important result for specifying heat flux boundary conditions in computational models.

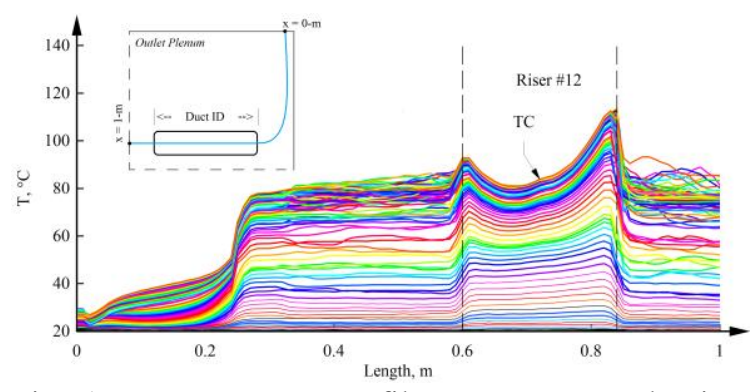

Fig. 19: Temperature profile across a sample riser outlet as measured by the LUNA fibers. Each line corresponds to one measurement in time.

\section{VIII.C. Thermal Characterization}

To more confidently assess the behavior of thermal-to-electric power ratio ("efficiency') with different testing conditions, a separate effects forcedflow test was performed. This test obtained trends for the efficiency for a number of combinations of mass flow rate and heater power, while allowing for greater control over inlet conditions than in typical natural convection cases. Fig. 20 demonstrates that the efficiency is around $65 \%$, with only small flowrate dependence. Results for the heated surface temperature, shown in earlier Fig. 13, are similar to those from the natural convection experiments. The efficiency is a very useful parameter for assessing integral behavior of the system, but more detailed thermal boundary conditions should be applied for CFD.

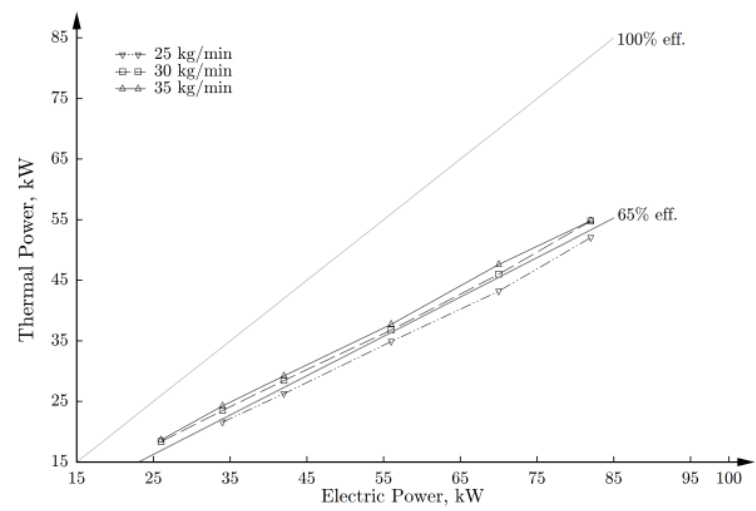

Fig. 20: Comparison of thermal to electric powers in the forced-flow separate effects test. 


\section{CONCLUSIONS}

Experiments have been conducted with the airbased NSTF at Argonne to evaluate the viability of a passive RCCS concept. After project initiation in 2010 , the project team began air-based data quality testing by early 2014 and has since completed over 1,300 hours of active test operations. The team has gained high confidence in the ability of the facility to conduct high quality tests across a wide range of conditions with sufficient instrumentation to adequately capture pertinent thermal hydraulic phenomena.

The test facility is most stable when operating at high powers in a single chimney configuration. At lower powers with dual chimney exhausts, the natural convection system may be unable to maintain symmetric flow out of the chimneys which can subsequently lead to de-graded heat removal performance. Perturbations at the outlet boundaries (e.g. strong wind gusts) may cause instabilities to form, leading to reverse flow situations where cool air is drawn down one chimney while hot air is exhausted out of the other. Engineering controls (e.g. damper valves) were used in order to reach the desired stable flow conditions, however these would not be available in a full scale implementation. These sensitive operational windows have been found to be limited to: a) start-up periods when the system is still thermally and hydraulically developing, and b) periods of low power removal by the NSTF.

Several of the newest additions to the instrumentation suite within the experimental test facility have been directly for the purposes of characterizing the facility while also supporting computational modeling. Parameters such as turbulence intensity, frictional losses, and velocity profiles are critical to accurately capturing physical phenomena for documentation purposes and implementation within a computer based model.

Additionally, the inclusion of high-resolution fiber optic temperature measurements is promising and supports the continued use in large scale thermal hydraulics test facilities. A more rigorous approach will be used in future testing for direct comparisons to CFD, and will entail a tight knit development of the sensor installation, an area that should be considered for future work. Nevertheless, the current findings were encouraging and have motivated the team to continue refining the measurement technique and explore new installation options.

\section{PATH FORWARD}

Testing in early 2016 will focus primarily on producing additional separate effects data to support computational modeling efforts. Parameters such as turbulence intensities and velocity profiles among various portions of the test facility have been highlighted as areas of interest and thus they will be pursued in greater depth. In parallel, efforts will be made to continue to study the alternative weather caps on the reduced scale facility with an aim to have an NSTF-ready solution designed and installed in the coming months. Low power and start-up testing will then be performed on a regular basis to expose the new chimney caps and chimney design to varying weather conditions to ascertain their effectiveness in mitigating flow reversals.

\section{ACKNOWLEDGMENTS}

The authors sincerely thank our colleagues at Argonne National Laboratory for their previous work on the design and analysis of NSTF, including Drs. Steve Lomperski, Constantine Tzanos, Tom Wei, W. Dave Pointer, and many summer students. This work was supported by the U.S. Department of Energy Office of Nuclear Energy's Advanced Reactor Technology (ART) program under contract number DE-AC02-06CH11357. 


\section{BIBLIOGRAPHY}

[1] A. Kraus, D. Lisowski, M. Bucknor, R. Hu, "Thermal-Hydraulic Simulation Framework for the NSTF and Preliminary Comparisons with Experimental Data," American Nuclear Society Winter Meeting, Washington DC, November 08 - 11, 2015.

[2] R. Hu and W. D. Pointer, "CFD Analyses of Natural Circulation in the Air-Cooled Reactor Cavity Cooling System,” Proceedings of M\&C 2013, Sun Valley, ID, May 5-9, 2013.

[3] M. M. Hecht, “MHTGR - nuclear engine or world development,” EIR, Vol. 16, 49, pp. 22 - 28, 1989.

[4] "Preliminary Safety Information Document for the Standard MHTGR," HTGR-86-024, Vol. 1, Amendment 13, U.S. Department of Energy, 1992.

[5] S. Lomperski, W. D. Pointer, C. P. Tzanos, T. Y. C. Wei and A. R. Kraus, "Generation IV nuclear energy system initiative. Air-Cooled Option RCCS Studies and NSTF Preparation," ANL-GenIV-179, Nuclear Engineering Division, Argonne National Laboratory, 2011.

[6] D. Lisowski, C. Gerardi, and M. Farmer, "Design and Scaling of the Natural convection Shutdown heat removal Test Facility", Proc. of ATH 2014, Reno, NV, June 15 - 19, 2014. ATH, 2014.

[7] D. Lisowski, M. T. Farmer, et al., "Design Report for the $1 / 2$ Scale Air-Cooled RCCS Tests in the Natural convection Shutdown heat removal Test Facility (NSTF)", ANL-SMR-8, 2015.

[8] J. H. Jo, J. H. Lim, S. Y. Song, M. S. Yeo, and K. W. Kim, "Characteristics of pressure distribution and solution to the problems caused by stack effect in high-rise residential buildings", Building and Environment, Vol. 42(1), 2007.

[9] J. H., Lienhard, K.N. Helland, "An experimental analysis of fluctuating temperature measurements using hotwires at different overheats", Exp. in Fluids, 7, 1989.

[10] S. Lomperski, C. Gerardi, D.W. Pointer, "Distributed fiber optic temperature sensing for CFD code validation", Proceedings of 15th International Topical Meeting on Nuclear Reactor Thermal Hydraulics (NURETH-15) Pisa, Italy, 2013.

[11] D. Lisowski, A. Kraus, M. Bucknor, R. Hui, "Separate Effects Characterization of the NSTF to Support Computational Modeling", Proc. of ANS Winter 2015, DC, Nov. 8-12, 2015. ANS 